\title{
Electrospun Polyhydroxyethyl-Aspartamide-Polylactic Acid Scaffold for Biliary Duct Repair: A Preliminary In Vivo Evaluation
}

\author{
S. Buscemi ${ }^{a, \star}$, G. Damiano ${ }^{\mathrm{b}}$, S. Fazzotta ${ }^{\mathrm{b}}$, A. Maffongelli $^{\mathrm{b}}$, V.D. Palumbo ${ }^{\mathrm{b}}$, S. Ficarella $^{\mathrm{b}}$, C. Fiorica $^{\mathrm{c}}$, \\ G. Cassata $^{d}$, M. Licciardi ${ }^{c}$, F.S. Palumbo ${ }^{c}$, L. Gulotta ${ }^{b}$, G. Buscemi ${ }^{b, e}$, and A.I. lo Monte ${ }^{b, e}$

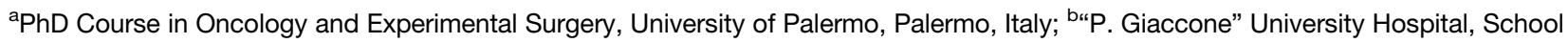 \\ of Medicine, University of Palermo, Palermo, Italy; 'Department of Biologic, Chemical, and Pharmaceutical Sciences and Technologies, \\ University of Palermo, Palermo, Italy; '“A. Mirri” Zooprophylactic Institute of Sicily, Palermo, Italy; and "Dichirons Department, University \\ of Palermo, Palermo, Italy
}

\begin{abstract}
Tissue engineering has emerged as a new approach with the potential to overcome the limitations of traditional therapies. The objective of this study was to test whether our polymeric scaffold is able to resist the corrosive action of bile and to support a cell's infiltration and neoangiogenesis with the aim of using it as a biodegradable tissue substitute for serious bile duct injuries. In particular, a resorbable electrospun polyhydroxyethylaspartamide-polylactic acid (90 mol\% PHEA, $10 \mathrm{~mol} \%$ PLA)/polycaprolactone (50:50 w/w) plate scaffold was implanted into rabbit gallbladder to assess the in vivo effects of the lytic action of the bile on the scaffold structure and then as a tubular scaffold to create a biliarydigestive anastomosis as well. For the above evaluation, 5 animals were used and killed after 15 days and 5 animals after 3 months. At 15-day and 3-month follow-ups, the fibrillar structure was not digested by lytic action bile. The fibers of the scaffold were organized despite being in contact with bile action. A new epithelial tissue appeared on the scaffold surface suggesting the suitability of this scaffold for future studies of the repair of biliary tract injuries with the use of resorbable copolymer on biliary injuries.
\end{abstract}

$\mathbf{E}^{x}$ XTRAHEPATIC biliary tract lesions occurring during laparoscopic cholecystectomy are burdened by perioperative morbidity and mortality [1,2], reduction of longterm survival [3], and reduction of the patient's quality of life $[4,5]$. Although the incidence of biliary injury during laparotomy is $0.1 \%-0.2 \%$ [6], in the case of the laparoscopic approach it becomes $\sim 2$-fold or even 3-fold higher [7].

Various attempts have been made to reconstruct the bile duct with the use of nonabsorbable vascular grafts, such as expanded polytetrafluoroethylene, with unsatisfactory results due to a high rate of stenosis, early-occurring infections, and long-term foreign body reactions [8-12]. Autologous grafts have been proposed as possible prosthetic material, but they showed extremely low results in the long term [13-16].

Rosen et al [17] described a method of biliary tree regeneration using the porcine small intestinal submucosa, another alternate material that does not involve any foreign body reaction but is burdened by the risk of zoonoses and abnormal wound healing $[18,19]$.
At present the criterion-standard surgical option is the creation of derivative biliary-digestive anastomoses: nevertheless, this kind of intervention does not restore a complete physiologic anatomy and is burdened by a high rate of morbidity and mortality with a consequent reduction in the patient's quality of life. The approach of regenerative medicine could be the most simple and effective solution for the repair of iatrogenic lesions of the biliary tract [20-23]. The tissue engineering approach requires the use of biodegradable scaffolds to allow cell recruitment from the

Funding: PRIN 2015: "Chirurgia rigenerativa nei difetti della parete addominale e nel deficit congenito o acquisito delle vie escretrici urinarie, biliari e dei vasi sanguigni: modellamento e crescita cellulare su scaffold planare e su scaffold tubulare. Studio sperimentale in vivo su modello suino" (2015X5AH3Z).

*Address correspondence to Salvatore Buscemi, University of Palermo, Via Del Vespro, 129, Palermo 90127, Italy. E-mail: buscemi.salvatore@gmail.com

$0041-1345 / 17$ http://dx.doi.org/10.1016/j.transproceed.2017.02.016 
boundary tissues, their proliferation stimulating new capillary formation in the first post-implantation phase and allowing the deposition of new extracellular matrix thanks to its progressive reabsorption [24]. Some polymeric materials have already been proposed as artificial substitutes of both natural and synthetic bile ducts $[25,26]$. Zong et al focused on the necessity of the scaffold not only being a passive conduit to allow bile flux, but also potentially supporting cell penetration, adhesion, and differentiation, as well as its degradation within the given time [27].

Our research group has proposed the use of electrospun biomaterials made of $\alpha, \beta$-poly $(N$-2-hydroxyethyl-D,L)aspartamide (PHEA)-polylactic acid (PLA) as scaffold for different regenerative purposes. Electrospun PHEA-PLA scaffolds were assayed in vitro to test the ability to support cell attachment and proliferation. Moreover, the chemical reactivity of PHEA repetitive units was exploited to link biologic effectors such as heparin and antiinflammatory drugs [28,29]. Recently, biocompatibility of hybrid fibers of PHEA-PLA/polycaprolactone (PCL) were tested in vivo in a murine model [30,31].

We report the first application of PHEA-PLA/PCL scaffolds in the repair of a biliary duct in an animal model. The aim was to test the scaffold resistance to the chemical action of bile juice and its ability to attract cell implantation as fibroblasts and neovascularization.

\section{METHODS}

The PHEA-PLA was synthesized according to a procedure described in previous works [32-34]. PCL was dissolved in a 50:50 $(\mathrm{v} / \mathrm{v})$ mixture of dichloromethane/dichloromethane with a concentration of $10 \%(\mathrm{w} / \mathrm{v})$. Then, the solution was used to dissolve PHEA-PLA copolymer to obtain a weight ratio of PHEA-PLA and PCL of 50:50. The electrospinning process was carried out horizontally with an accelerating voltage ranging from 20 to $25 \mathrm{kV}$ and a constant polymeric solution rate of $1 \mathrm{~mL} / \mathrm{h}$. The electrospun scaffold was collected on aluminum foil wrapped around an grounded rotating collector $(200 \mathrm{rpm}) 10-20 \mathrm{~cm}$ from the tip of the needle. The resulting fibrillar scaffold was washed with double-distilled water then dried under vacuum at room temperature for 4 days.

Ten New Zealand white male rabbits weighing $\sim 1.5 \mathrm{~kg}$ were used. The animals were sedated with the use of intramuscular injections of $80 \mathrm{~g} / \mathrm{kg}$ medetomidine and a solution of tiletamine and zolazepam to $4 \mathrm{mg} / \mathrm{kg}$; anesthesia was induced and maintained with the use of a gaseous mixture of isoflurane and oxygen administered by means of facemask. After a median laparotomy, each rabbit's gallbladder was isolated and incised. The gallbladder was washed and a PHEA-PLA/PCL patch $(1 \mathrm{~cm} \times 1 \mathrm{~cm})$ was inserted in the organ. The scaffold was then secured to the wall, including part of it in the suture of the previously performed incision. The median laparotomy was then closed and the animals kept fasting for the following 12 hours. An antibiotic was administrated for 4 days after the intervention. Fifteen days after the intervention, 4 rabbits were killed, and the scaffold patch taken from the animals' gallbladder was cleaned by means of repeated washings with a physiologic saline solution for it to be analyzed with the use of scanning electron microscopy (SEM) and a histologic examination. The same procedure was repeated after 3 months for the other group of 4 animals. Two animals were used as control in which no

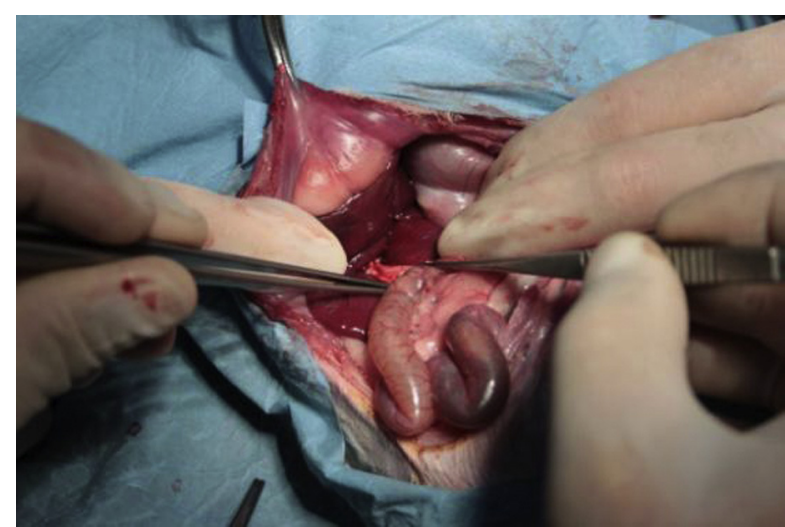

Fig 1. Biliodigestive anastomosis with the use of PHEA-PLA/ PCL tubular scaffold.

implantation was carried out; they were subsequently killed at 15 days and 3 months. In the 2nd part of our experiment, 4 New Zealand white male rabbits weighing $\sim 1.5 \mathrm{~kg}$ were used. After the sedation and the induction of anesthesia in the rabbits, we performed a biliary-digestive anastomosis between the fundus of the gallbladder and the second duodenal portion. After ligation of the common bile duct, we carried out an anastomosis with the interposition of the PHEA-PLA/PCL tubular scaffold, sutured with the use of polypropylene 7-0 (Fig 1).

An antibiotic was administrated for 4 days after the intervention. Three months after the intervention, all of the rabbits were killed and the scaffold taken en bloc from each animal's abdomen. One animal was used as control.

All animal experiments were in compliance with the Animal Research: Reporting of In Vivo Experiments guidelines and were carried out in accordance with the EU Directive 2010/63/EU guidelines for animal experiments, the National Institutes of Health guide for the care and use of laboratory animals (legislative decree no 26, March 4, 2014) and the Organismo Preposto al Benessere Animale of the "A. Mirri" Zooprophylactic Institute.

Five- $\mu \mathrm{m}$ thick sections were obtained from the formalin-fixed paraffin-embedded samples 3 months after the implantation; they were then set on slides treated with silane (3-aminopropyl-trieossisilane) to avoid detachment during staining. The preparations obtained were dried overnight in an oven at $37^{\circ} \mathrm{C}$, then a dewaxing with the use of xylene was performed for 20 minutes. After a descending alcohol series $(100 \%, 95 \%, 75 \%$, and $50 \%)$, the slides were washed in distilled water and then stained with hematoxylin and eosin. This was followed by the ascending scale of alcohols $(50 \%, 75 \%, 95 \%$, and $100 \%)$ and clarification in xylene. After this phase, the slides were mounted in an acrylic mounting medium (Eukitt; O. Kindler).

\section{RESULTS}

SEM analysis revealed that the side of the scaffold patch in contact with the gallbladder lumen appeared interpenetrated with cellular and extracellular materials. The side pointed toward the lumen of the gallbladder maintained its fibrillarity. The fibers appeared unchanged in form and dimension and showed uniformity in size and absence of fusion among each other. The 3-dimensional microfibrillar structure of the scaffold patch was maintained and 

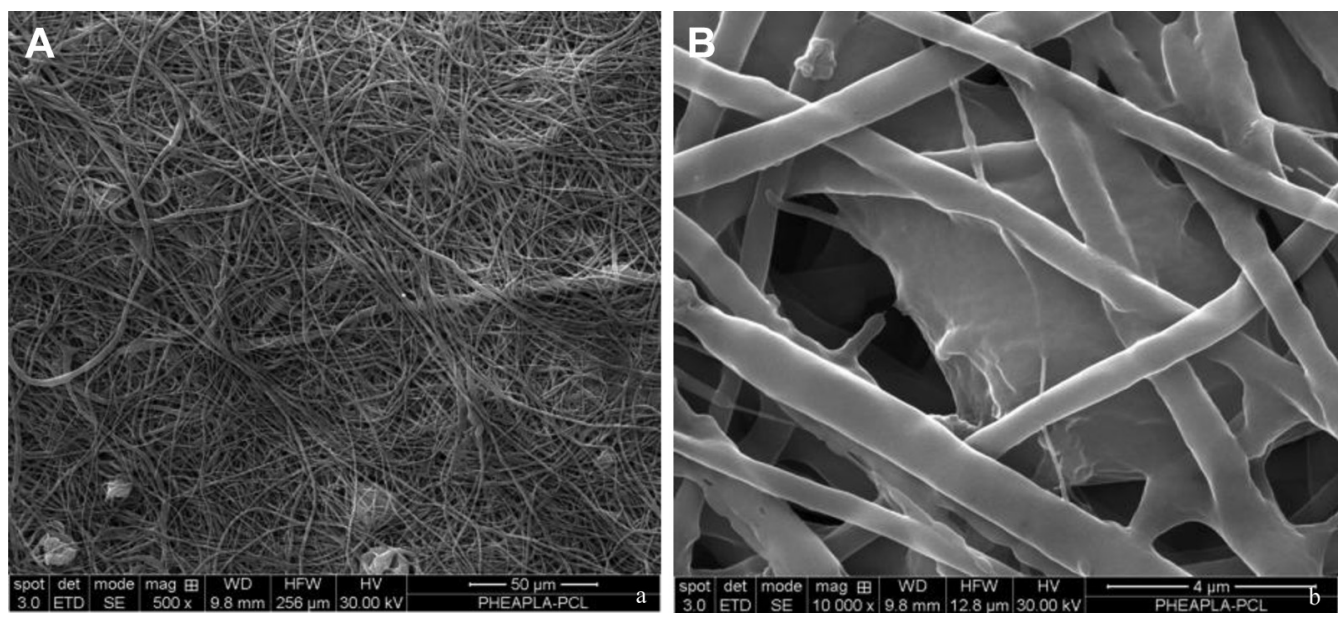

Fig 2. (A) SEM image of PHEA-PLA PCL scaffold after 15 days of implantation in rabbit gallbladder ( $\times 500)$. (B) SEM image of PHEAPLA/PCL scaffold after 3 months of implantation in rabbit gallbladder $(\times 10,000)$.

therefore was not damaged by the lytic action of bile after 15 days nor after 3 months (Fig 2).

The eosin-hematoxylin stain of samples excised from the gallbladder after 3 months showed that the electrospun scaffold was covered with the mucosal tissue and a correct stratification of epithelial cells. The boundary between epithelia and scaffold was clearly visible and looked like a cellular infiltration on the scaffold made up of fibrous tissue and inflammatory cells (Fig 3A). At higher magnification, it was possible to observe lymphocytes, macrophages, and giant cells in the cellular infiltrate (Fig 3B). This aspect was consistent with a foreign body reaction elicited by the scaffold. In Fig $3 \mathrm{C}$ it is possible to observe the formation of neovasa in the scaffold.

In the samples of tubular scaffold 3 months after implantation, there was the presence of inflammatory cells
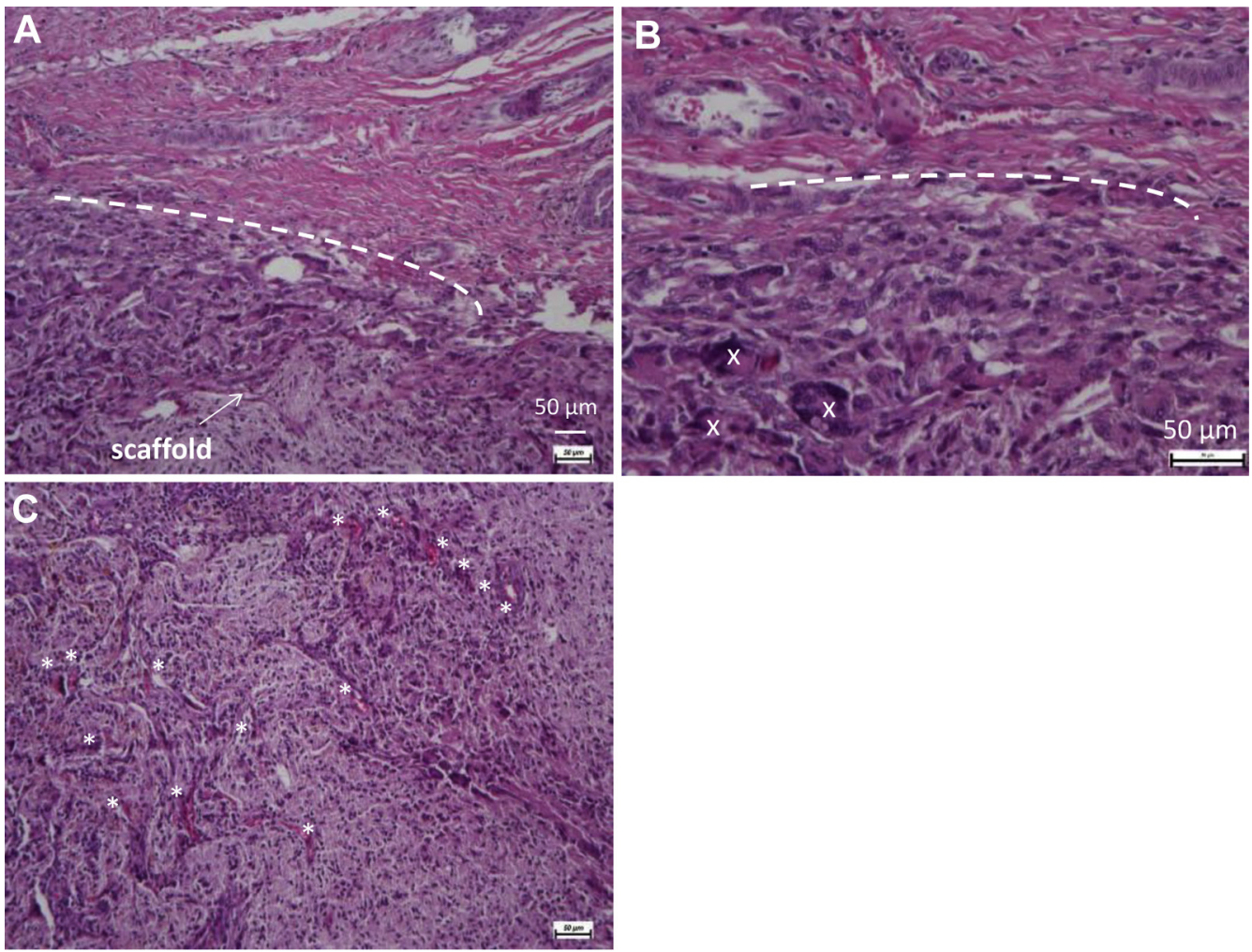

Fig. 3. Eosin-hematoxylin stain of samples excised after 3 months. 


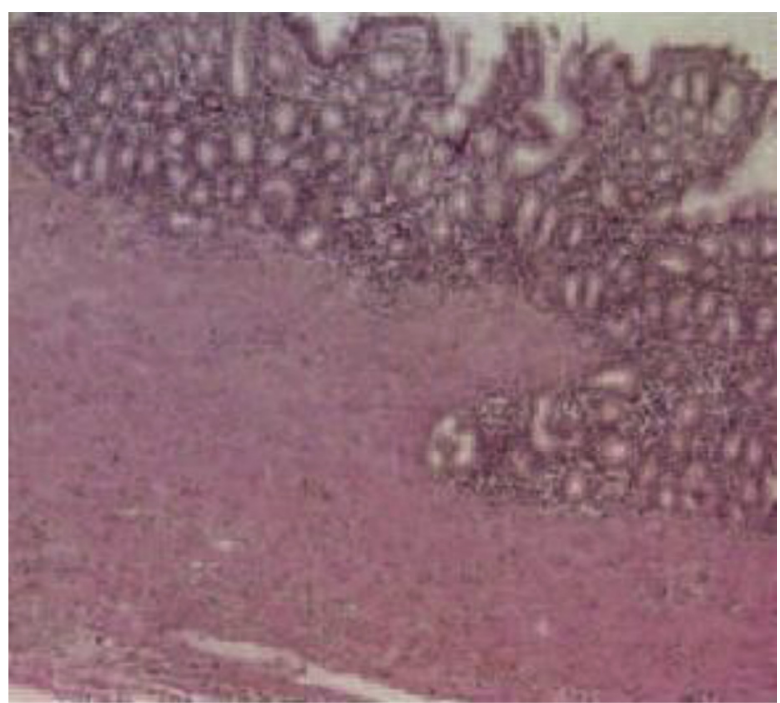

Fig 4. Eosin-hematoxylin stain of tubular scaffold samples excised after 3 months, showing accessory gland cells under the neo-epithelium $(\times 100)$.

with cellular elements positive for CK19. Under the epithelium of the neo bile duct there was a large number of accessory gland cells (Fig 4). There were no differences in epithelialization among the duodenal end, the central portion, and the gallbladder end (Fig 5).

\section{DISCUSSION}

With the advent of tissue engineering, the application of completely resorbable biocompatible materials has become an attractive investigational field for their potential in repairing or replacing nonfunctioning organs damaged by aging or toxic agents $[35,36]$.

Interesting scenarios are opened up by the possibility of obtaining tubular resorbable scaffolds capable of promoting the migration of the surrounding epithelium as a subsequently reabsorbed extracellular matrix, substituted with the native tissue. The repair of biliary tree lesions with these scaffolds has already been partially demonstrated by several studies, particularly by Japanese authors. A group from Saitama Medical University proposed the use of a copolymer of PLA and PCL reinforced with fibers of polyglycolic acid [24]. The results at 6 months are encouraging, because total resorption of the material used and formation of a

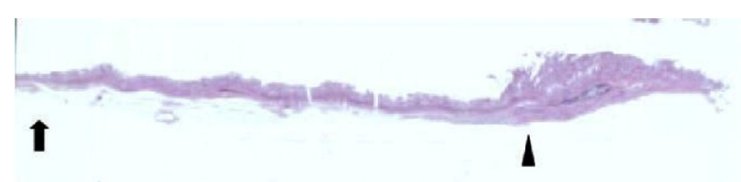

Fig 5. Longitudinal section of the neo-bile duct after 3 months of implantation. Arrow and arrowhead show two different tracts of mucosa in the same longitudinal section. tissue completely uniform to the native anatomic structures of the animal were noted.

The starting material of our scaffold is PHEA, a biocompatible synthetic polymer soluble in water with a structure similar to that of proteins. This macromolecule was used for the synthesis of a PHEA-PLA copolymer, which was obtained by the chemical binding of PHEA with the biodegradable polymer PLA and of PLA with ethylenediamine. The electrospinnable PHEA-PLA was then mixed with another biodegradable polymer, PCL, in such a way as to enable affinity to the physiologic medium, chemical versatility, and mechanical resistance to coexist in the same material.

The data obtained from in vivo experiments showed that the material has good biocompatibility, evoking an inflammatory response of modest degree, which has a key role in the resorption of the material and in tissue regeneration, leading to the migration of stem cells. The scaffold used for this specific application had a length of $\sim 1 \mathrm{~cm}$, and its fibers had pores with a diameter ranging from $500 \mathrm{~nm}$ to $1 \mu \mathrm{m}$.

The 3-dimensional scaffold (PHEA-PLA/PCL) presenting the final form of microfibrillar laminae was tested in this 2nd phase for its ability to withstand the chemical action of bile. The data obtained after 15 days and 3 months of implantation demonstrated that this electrospun scaffold could be a potential candidate as substitute for the biliary tree affected by injuries, because it shows good tissue integration and is resistant to the early lytic phenomena that degrade the scaffold before complete colonization of cells, as occurs for different scaffolds already tested for this purpose.

After 3 months, the scaffold was recovered to assess its biologic behavior toward the cellular constituents of the gallbladder wall. The success of the present experiment was essentially based on the demonstration of the resistance of the scaffold to an aggressive environment, making it an ideal candidate for the reparation of bile tract injuries.

\section{CONCLUSION}

Our biliary prosthetic material lends itself well to the treatment of extrahepatic biliary tract injuries, because, from the 1st data obtained, it was shown that the patch is able to maintain its structural integrity. Its constituent fibers remain uniform and well organized, suggesting that this type of material can withstand the corrosive action of bile acids.

These early results are of fundamental importance and will lead us to carry out future studies that take into account the ability of the scaffold to stimulate the homing of circulating stem cells and the behavior of the cells placed in direct contact with the material.

\section{REFERENCES}

[1] Savader SJ, Lillemoe KD, Prescott CA, Winick AB, Venbrux AC, Lund GB, et al. Laparoscopic cholecystectomyrelated bile duct injuries: a health and financial disaster. Ann Surg 1997;225:268-73. 
[2] Moossa AR, Mayer AD, Stabile B. Iatrogenic injury to the bile duct. Who, how, where? Arch Surg 1990;125:1028-31.

[3] Flum DR, Cheadle A, Prela C, Dellinger EP, Chan L. Bile duct injury during cholecystectomy and survival in medicare benificiaries. JAMA 2003;290:2168-73.

[4] Boerma D, Rauws EA, Keulemans YC, Bergman JJ, Obertop H, Huibregtse K, et al. Impaired quality of life 5 years after bile duct injury during laparoscopic cholecystectomy: a prospective analysis. Ann Surg 2001;234:750-7.

[5] Moore DE, Feurer ID, Holzman MD, Wudel LJ, Strickland C, Gorden DL, et al. Long-term detrimental effect of bile duct injury on health-related quality of life. Arch Surg 2004; 139:476-82.

[6] Parmeggiani D, Cimmino G, Cerbone D, Avenia N, Ruggero R, Gubitosi A, et al. Biliary tract injuries during laparoscopic cholecystectomy: three case reports and literature review. G Chir 2010;31:16-9.

[7] Kholdebarin R, Boetto J, Harnish JL, Urbach DR. Risk factors for bile duct injury during laparoscopic cholecystectomy: a case-control study. Surg Innov 2008;15:114-9.

[8] Bandura WP, Arbulu A. Experimental replacement of the common bile duct with Teflon graft. Am Surg 1961;27:518-24.

[9] Gomez NA, Alvarez LR, Mite A, Andrade JP, Alvarez JR, Vargas PE, et al. Repair of bile duct injuries with Gore-Tex vascular grafts: experimental study in dogs. J Gastrointest Surg 2002;6:116-20.

[10] Christensen M, Laursen HB, Rokkjaer M, Jensen PF, Yasuda Y, Mortensen FV. Reconstruction of the common bile duct by a vascular prosthetic graft: an experimental study in pigs. J Hepatobiliary Pancreat Surg 2005;12:231-4.

[11] Mendelowitz DS, Beal JM. Expanded polytetrafluoroethylene in reconstruction of the canine biliary system. Am J Surg 1982;143:221-4.

[12] Schanaider A, Pannain VL, Müller LC, Maya MC. Expanded polytetrafluoroethylene in canine bile duct injury: a critical analysis. Acta Cir Bras 2011;26:247-52.

[13] Bottger T, Mann B, Pickel B, Weber W, Sorger K, Junginger T. Animal experiment studies of pedicled small intestine transplantation as partial extrahepatic bile duct replacement. Langenbecks Arch Chir 1991;376:77-84.

[14] Belzer FO, Watts JM, Ross HB, Dunphy JE. Auto-reconstruction of the common bile duct after venous patch graft. Ann Surg 1965;162:346-55.

[15] Aydin M, Bakir B, Kosem M, Kisli E, Genccelep M. Biliary tract reconstruction with autologous rectus sheath graft-an experimental study. Hepatogastroenterology 2005;52:1019-22.

[16] Sedgwick CE. Reconstruction of the common bile duct with a free ureteral graft; an experimental study. Surg Gynecol Obstet 1951;92:571-3.

[17] Rosen M, Ponsky J, Petras R. Small intestinal submucosa as a bioscaffold for biliary tract regeneration. Surgery 2002;132:480-6.

[18] Gomez NA, Zapatier JA, Vargas PE. Small intestinal submucosa as a bioscaffold for biliary tract regeneration. Surgery 2004;135:460.

[19] El-Assmy A, Hafez AT, El-Sherbiny MT, El-Hamid MA, Mohsen T, Nour EM, et al. Use of a single layer small intestinal submucosa for long segment ureteral replacement: a pilot study. J Urol 2004;171:1939-42.

[20] Aikawa M, Miyazawa M, Okamoto K, Toshimitsu Y, Okada K, Akimoto N, et al. An extrahepatic bile duct grafting using a bioabsorbable polymer tube. J Gastrointest Surg 2012;16:529-34.
[21] Miyazawa M, Torii T, Toshimitsu Y, Okada K, Koyama I, Ikada Y. A tissue-engineered artificial bile duct grown to resemble the native bile duct. Am J Transplant 2005;5:1541-7.

[22] Aikawa M, Miyazawa M, Okada K, Toshimitsu Y, Torii T, Otani Y, et al. Regeneration of extrahepatic bile duct-possibility to clinical application by recognition of the regenerative process. J Smooth Muscle Res 2007;43:211-8.

[23] Del Gaudio C, Baiguera S, Ajalloueian F, Bianco A, Macchiarini P. Are synthetic scaffolds suitable for the development of clinical tissue-engineered tubular organs? J Biomed Mater Res A 2013;102:2427-47.

[24] Aikawa M, Miyazawa M, Okamoto K, Toshimitsu Y, Torii T, Okada K, et al. A novel treatment for bile duct injury with a tissue-engineered bioabsorbable polymer patch. Surg 2010;147: $575-80$.

[25] Xu X, Liu T, Zhang K, Shen Z, Li Y, Jing X. Biodegradation of poly(1-lactide-co-glycolide) tubestents in bile. Polym Degrad Stabil 2008;93:811-7.

[26] Nakashima S, Nakamura T, Miyagawa K, Yoshikawa T, Kin S, Kuriu Y, et al. In situ tissue engineering of the bile-duct using polypropylene mesh-collagen tubes. Int J Artif Organs 2007;30: 75-85.

[27] Zong C, Wang M, Yang F, Chen G, Chen J, Tang Z, et al. A novel therapy strategy for bile duct repair using tissue engineering technique: PCL/PLGA bilayered scaffold with hMSCs. J Tissue Eng Regen Med 2015. Published online February 5, 2015.

[28] Pitarresi G, Fiorica C, Palumbo FS, Rigogliuso S, Ghersi G, Giammona G. Heparin functionalized polyaspartamide/polyester scaffold for potential blood vessel regeneration. J Biomed Mater Res A 2014;102:1334-41.

[29] Pitarresi G, Fiorica C, Palumbo FS, Calascibetta F, Giammona G. Polyaspartamide-polylactide electrospun scaffolds for potential topical release of Ibuprofen. J Biomed Mater Res A 2012;100(A part 6):1565-72.

[30] Abruzzo A, Fiorica C, Palumbo VD, Altomare R, Damiano G, Gioviale MC, et al. Using polymeric scaffolds for vascular tissue engineering. Int J Polymer Sci 2014;2014:689390.

[31] lo Monte AI, Licciardi M, Bellavia M, Damiano G, Palumbo VD, Palumbo FS, et al. Biocompatibility and biodegradability of electrospun PHEA-PLA scaffolds: our preliminary experience in a murine animal model. Digest J Nanomater Biostruct 2012; 7:841-51

[32] Pitarresi G, Palumbo FS, Fiorica C, Calascibetta F, Giammona G. Electrospinning of $\alpha, \beta$-poly(N-2-hydroxyethyl)-DLaspartamide-graft-polylactic acid to produce a fibrillar scaffold. Eur Polymer J 2010;46:181-4.

[33] Fiorica C, Palumbo FS, Pitarresi G, Giorgi M, Calascibetta F, Giammona G. In-situ forming gel-like depot of a polyaspartamide-polylactide copolymer for once a week administration of sulpiride. J Pharm Pharmacol 2014;67:78-86.

[34] Pitarresi G, Palumbo FS, Albanese A, Licciardi M, Calascibetta F, Giammona G. In situ gel forming graft copolymers of a polyaspartamide and polylactic acid: preparation and characterization. Eur Polymer J 2008;44:3764-75.

[35] Haseltine WA. Regenerative medicine 2003: an overview. J Regen Med 2003;4:15-8.

[36] Daar AS. Regenerative medicine: a taxonomy for addressing ethical, legal and social issues. In: Gutmann T, Daar AS, Sells RA, Land W, editors. Ethical, legal, and social issues in organ transplantation. Munich: Pabst; 2005. p. 368-77. 